\title{
Serbest Dolaşımlı (Free Range) ve Derin Altlık Barındırma Sisteminin Yavaş ve Hızlı Gelişen Etlik Piliçlerde Büyüme Performansı ve Ekonomik Verimlilik Üzerine Etkisi*
}

\author{
Ibrahima Mahamane ABDOURHAMANE ${ }^{1, a}$, Metin PETEK $^{1, b, * *}$ \\ ${ }^{1}$ Bursa Uludağ Üniversitesi Veteriner Fakültesi Zootekni Anabilim Dalı, Bursa, Turkiye. \\ aORCID: 0000-0003-4560-2438, bORCID: 0000-0001-8789-3101
}

\begin{abstract}
Özet: Bu çalışma, serbest dolaşımlı (free-range) barındırma sisteminin yavaş ve hızlı gelişen etlik piliçlerde büyüme performansı ve ekonomik verimlilik üzerine etkisini incelemek amacıyla yapılmıştır. Çalışmada yavaş ve hızlı gelişen iki ayrı etlik piliç genotipi ile serbest dolaşımlı (free range) ve geleneksel derin altık zemin sistemi olmak üzere dört ana grup yer almış $(2 \times 2)$ ve her ana grup 5 tekrarlı gruptan oluşmuştur. Her tekrarlı grupta 10 adet civciv olmak üzere çalışmada toplamda 200 adet günlük yaşta erkek civciv kullanılmış, gruplarda canlı ağırlık, yem tüketimi ve ölenler kaydedilmiş, değişken giderler ve bu giderlerin toplam içindeki payları belirlenmiş, brüt kar ve karlılık oranı hesaplanmıştır. Araştırma sonu (56 günlük yaş) canlı ağılık $(P<0.009)$ ve yemden yararlanma oranı $(P<0.01)$ bakımından barındırma sisteminin etkisi önemli bulunmuş, hızlı gelişen genotiplerin deneme sonu canlı ağırlık $(P<0.001)$ ve yemden yararlanma yeteneği $(P<0.006)$ yavaş gelişenlere göre daha yüksek bulunmuştur. Genel olarak, serbest dolaşımlı (free-range) barındırmada yavaş ve hızlı gelişen piliçlerin her ikisinin de büyüme ve ekonomik performansı derin altlık sistemde yetiştirilenlere göre daha yüksek bulunmuştur. Elde edilen sonuçlara göre, hızlı gelişen piliçlerin serbest dolaşımlı free-range piliç eti üretiminde, yavaş gelişen piliçlerin konvansiyonel piliç eti üretiminde kullanımının giderek yaygınlaşacağı beklenebilir.
\end{abstract}

Anahtar Kelimeler: Etlik piliç, Barınak, Genotip, Büyüme performansı, Ekonomik verimlilik.

\section{Effects of Free-Range and Deep Litter Housing System on Growth Performance and Production Economics of Slow and Fast-Growing Broiler}

This study aimed to evaluate the effects of free-range housing system on growth performance and production economics of slow and fast-growing broiler. In the study, slow-growing and fast-growing broilers with slatted floor and deep litter were used, so there were four main groups $(2 \times 2)$, and each main group was consisted of 5 replicates. Each replicates was consisted of 10 male day-old ages chicks so 200 birds were used in total. The experiment lasted in 56 days. In the study, live weight gain, feed consumption, and death of birds were recorded throughout the experiment. Variable costs of each group and their percentages within total costs were calculated, gross profit and profitability were calculated to analyze economic performance. As expected, the body weight and feed conversion ratio of fast-growing broiler was found to be better than slower growings $(P<0.001, P<0.006)$, and the effect of the housing system on live body weight and feed conversion ratio was found to be significantly important $(P<0.009, P<0.01)$. In general, the growth and economic performance of both slow and fast-growing broilers in free-range housing were higher than those raised in conventional deep litter system. According to the results, the use of fast-growing broilers in free-range production and the use of slow-growing broilers in conventional production can be expected to become widespread.

Keywords: Broiler, Economics, Free range housing, Genotype, Growth performance.

\section{Giriş}

Piliç eti üretimi dünya genelinde derin altlıklı kümeslerde gerçekleştirilmektedir (North ve Bell, 1990). Derin altlıklı kümeslerde hayvanların hareket alanının sınırlı olması ve doğal gün ışı̆̆ından yararlanamamaları, doğal ve organik ürünlere olan tüketici talebinin giderek artması gibi nedenlerden piliç eti üretiminde serbest dolaşımlı free range gibi değişik barındırma ve yetiştirme sistemlerine olan ilgi giderek artmaktadır (Anonim, 2007). Ingiltere' de toplam piliç eti üretiminin $\% 3,5^{\prime}$ i serbest dolaşımlı free-range sistemde gerçekleştirilmektedir
(British Poultry Council, 2017). Türkiye' de 2019 verilerine göre 7.807 ticari etlik piliç işletmesi ve 12.725 etlik piliç kümesi bulunmakta olup (Anonim, 2020) tamamına yakınının geleneksel derin altlıklı kümes olduğu düşünülmektedir. Serbest dolaşımlı (free-range) barındırma sistemi, doğal piliç etine olan talebin ve hayvan refahı konusunda tüketici duyarlıı̆ı̆ının artmasıyla yaygınlaşan alternatif bir sistemdir (Jones ve Berk., 2012). Bu yetiştirme sistemi kanatlı hayvanların kapalı barınakta barındırılması ve açık alanda serbest olarak 
otlatılması esasına dayanmakta olup, barınak derin altlıklı kapalı bir bölüm ile gezinti alanı olmak üzere iki bölümden oluşmaktadır. Gezinti alanı yeşillendirilmiş çayır mera alanı ve yalnızca toprak veya kumla kaplanmış gezinti alanı olarak planlanabilmektedir (Appleby ve ark., 1992; Yenilmez ve Uruk, 2016). Serbest dolaşmlı free range barındırma sisteminde kapalı alan ve gezinti alanında hayvan başına olması gereken zemin alanı konusunda tam bir benzerlik olmayıp, ülkelere göre farklı uygulamalar olabilmektedir (Taylor ve ark., 2018). Serbest dolaşımlı alternatif sistemlerde besleme programı üretim yönüne göre farklı olabildiği gibi, bu barındırma sisteminin sera gazı salınımı, toprak ve çevreye olan etkileri de farklıdır (Da Silva ve ark., 2014). Serbest dolaşımlı free range kümesler sabit olabildiği gibi hareketli de olabilmekte (Grandin, 2015), hayvanlar sıcak ve soğuk stresi, aşırı parlak ışık, yağmur gibi hayvan sağlığı ve refahını etkileyen faktörlerin daha fazla etkisi altındadır (Ponte, 2008). Bu sistemde yetiştirilen kanatlılar merada otlanma, böcek ve solucan avlama ile yoğun fiziksel aktivite imkânlarına sahip olup (Van Horne ve Achterbosch, 2008), hayvanlara geleneksel sistemlerde yaşayamadıkları doğal davranışlarını yaşama, güneş ışınından yararlanma fırsatı da sağlanmış olur. Serbest dolaşımlı sistemde kümes içi alanda hayvanlara daha geniş ve rahat bir ortam sağlanmaktadır. Ancak bu sistemde daha fazla araziye ihtiyaç vardır ve piliç eti üretim maliyetleri daha yüksek olabilmektedir. Bu barındırmada gezinti alanında yer alan zararlı ot ve bitkilerden tavuklar olumsuz etkilenebilmekte (Miao ve ark., 2005), yabani hayvan saldırılarına daha açık olmakta, hayvanlarda korku davranışına daha fazla rastlanılmaktadır. Serbest dolaşımlı free-range barındırmada hayvanların enfeksiyöz hastalıklara yakalanma ihtimali daha yüksektir. Beslenme yetersizlikleri ile daha sık karşılaşılmakta olup, hayvanların merada tükettiği ot miktarının ve besleyici değerinin hesaplanması daha güçtür (Yenilmez ve Uruk, 2016).

Piliç eti üretiminde uygun koşullarda barındırma yanında hayvanın genetik yapısı verimliliği etkileyen en önemli faktörlerden birisi olup, ticari üretimde yaygın olarak hızlı gelişen etlik piliç genotipleri kullanılmaktadır. Genetik olarak yavaş ya da orta düzeyde gelişme kabiliyeti olan etlik piliç genotipler ise daha çok organik tarım gibi sertifikalı ve alternatif üretimlerde kullanılmaktadır (Moyle ve ark., 2014). Bu piliçlerde daha yavaş gelişme yanında; hızlı gelişen piliçlere göre ani ölüm sendromu ve ayak problemleri görülme oranı daha düşüktür (Karaarslan, 2015; Çavuşoğlu ve Petek, 2019). Türkiye' de serbest ya da gezen piliç adı altında free-range barındırma sisteminde piliç eti üretimi az da olsa yapılmakta olup, organik ya da organik olmayan koşullarda yavaş gelişen etlik piliç genotipleri ticari olarak kullanılmaya başlanmıştır (Ceylan, 2018). Yavaş gelişen etlik piliç genotiplerinin hem serbest dolaşımlı free-range üretimde hem de kapalı barındırma koşullarında verim performanslarının belirlenmesinin, özellikle ticari entansif üretimde hızlı gelişen genotipler ile performanslarının eşdeğer koşullarda ortaya konulmasının faydalı olacağı düşünülmektedir. Hollanda, İngiltere ve Amerika Birleşik Devletleri gibi bazı ülkelerde üreticiler free range ve organik sistemlerde hızlı gelişen etlik piliç genotiplerini tercih etse de (Poltowicz ve Doktor 2011) yavaş gelişen etlik piliçlerin uygun olmayan çevresel koşullara dayanıklı ve yüksek otlama davranışı nedeniyle alternatif sistemlerde kullanılmasının daha uygun olacağı bildirilmiştir (Moyle ve ark., 2014; Legrand ve ark., 2017). Etlik piliç genotiplerinin mera kullanımı farklı olup, yavaş gelişen genotiplerin daha yüksek mera kullanımı ve ot tüketim oranına sahip oldukları tespit edilmiştir (Fanatico, 2007). Serbest dolaşımlı free range üretim sisteminde yetiştirilen hayvanların büyüme performansının araştırılarak bu üretim sistemine en uygun piliç genotipinin belirlenmesine dönük çalışmalara büyük ihtiyaç olduğu düşünülmektedir. $\mathrm{Bu}$ çalışma serbest dolaşımlı free-range ve geleneksel derin altlıklı kümeslerde yetiştirilen yavaş ve hızlı gelişen genotiplerin karşılaştırmalı olarak büyüme performansları ile üretim ekonomisi üzerine etkilerini araştırmak amacı ile planlanmıştır.

\section{Materyal ve Metot}

Yönetim: Çalışmada 4 ana grup oluşturulmuş ( 2 genotip x 2 barındırma sistemi) ve her ana grupta 5' er tekrarlı alt grup olmak üzere denemede toplamda 20 grup yer almıştır. Denemede yavaş gelişen genotip olarak; Hubbard JA57 ve hızlı gelişen genotip olarak Ross 308 kullanılmıştır. Serbest dolaşımlı free-range gruplar kapalı bölüm ve gezinti/otlama bölümünden oluşurken, derin altlık gruplar sadece kapalı bölümden oluşmuştur. Her iki grupta da kapalı bölümler derin altlık olarak düzenlenmiştir. Gruplarda kapalı bölümler 1x1 m, serbest dolaşımlı free range grubun gezinti/otlama alanlarının her biri ise $1 \times 5 \mathrm{~m}$ ölçülerinde planlanmıştır. Her tekrarlı alt grupta 10, her ana gurupta 50 adet günlük yaşta civciv olacak şekilde; çalışmada toplam olarak 100 adet yavaş gelişen ve 100 adet hızlı gelişen erkek etlik civciv kullanılmıştır.

Derin altlıklı ve serbest dolaşımlı sistemin kapalı bölümünde altlık olarak bir metrekare alanda 7 kg olacak şekilde yaklaşık $10 \mathrm{~cm}$ kalınlığında pirinç kavuzu kullanılmıştır. Deneme öncesi, deneme alanı 
ile deneme süresince kullanılacak bütün ekipmanlar temizlenip dezenfekte edilmiş ve kuruması sonrası altlık materyali ve ekipmanlar deneme bölümlerine yerleştirilmiştir. Denemenin ilk haftasında bütün gruplarda civciv yemlik ve suluğu, sonrasında $10 \mathrm{~kg}$ yem kapasitesine sahip olan askılı plastik yemlik ve askılı yuvarlak suluklar kullanılmıştır. Deneme süresince gruplarda bulunan hayvanlar; etlik piliçler için standart koşullarda büyütülmüşler (North ve Bell, 1990). Deneme başlangıcında gruplarda yer alan hayvanlara civciv seviyesinde $33-35^{\circ} \mathrm{C}$ sıcaklık sağlanmış, sonrasında haftalık $3.5-4.0{ }^{\circ} \mathrm{C}$ azaltılarak 4. haftadan sonra $18-21{ }^{\circ} \mathrm{C}^{\prime}$ de sabit tutulmuştur. Gezinti/otlama alanı dış ortam sıcaklığı ise gün içinde $20-30{ }^{\circ} \mathrm{C}$ arasında değişmiştir. Denemenin ilk 4 haftasında \%40-60, sonraki haftalarda \%30-40 düzeyinde iç ortam rutubeti sağlanmış, hayvanlar özel bir yem fabrikasından temin edilen dört farklı ticari konsantre yem ile ad-libitum beslenmişlerdir. Gruplarda yer alan hayvanlara 10 günlük yaşa kadar küçük taneli pelet formda etlik civciv başlangıç (\%23 protein, $2950 \mathrm{kcal} / \mathrm{kg} \mathrm{ME)}$, 11-23. günler arası pelet formda etlik civciv büyütme (\%21 protein, 3000 $\mathrm{kcal} / \mathrm{kg} \mathrm{ME),} \mathrm{24-36.} \mathrm{günler} \mathrm{arası} \mathrm{pelet} \mathrm{formda} \mathrm{etlik}$ piliç büyütme (\%20 protein, $3050 \mathrm{kcal} / \mathrm{kg} \mathrm{ME}$ ), 37. günden kesime kadar pelet formda kesim öncesi yem (\%19 protein, $3100 \mathrm{kcal} / \mathrm{kg} \mathrm{ME}$ ) verilmiştir. Denemede kullanılan serbest dolaşımlı free range sistemde doğal gezinti/otlama alanının botanik kompozisyonu Los Pasos metodu ile belirlenmiş (Anonim, 1980), gezinti/otlama alanının \%40' dan daha azı yonca gibi yem bitkilerilerinden, çoğunluğu pıtrak gibi doğal bitkilerden oluştuğundan "zayıf mera" kategorisinde değerlendirilmiştir (Çelik 2015). Deneme ünitelerinin tünel havalandırma sistemi $\quad\left(0.080-2.444 \quad \mathrm{~m}^{3} / \mathrm{saat}\right.$ minimum havalandırma oranı, Aviagen 2018) ve petek-fan serinletme sistemi ile havalandırma ve serinletme ihtiyaçları karşılanmış, ünitenin kuzey tarafında yer alan gezinti bölümünün üzeri özel bir file ile kapatılarak gölgelik sağlanmış, aynı zamanda kuşların girmesi de engellenmiştir.

Veri Toplama: Deneme başlangıcında civcivler bireysel olarak tartılarak kuluçka çıkım ağırlıkları belirlenmiş ve guruplara rastgele dağıtılmışlar, deneme sonu canlı ağırlığı bireysel tartımlar ile belirlenmiştir. Deneme başında her gruba 5' er kg yem ayrılmış, sonrasında gerektikçe $5^{\prime}$ er $\mathrm{kg}$ yem ilave edilmiştir. Deneme sonu gruplarda kalan yemler tartılarak verilen toplam yem miktarından çıkarılmış ve toplam yem tüketimi dönem başı hayvan sayısına bölünerek (tavuk-kümes) piliç başına yem tüketimi bulunmuştur. Piliç başına ortalama yem tüketimi ortalama canlı ağırlığa bölünerek yemden yararlanma hesaplanmıştır. Gruplarda ölümler olduğunda kaydedilmiş, yaşayan hayvan sayısının başlangıçtaki hayvan sayısına bölünmesiyle yaşama gücü hesaplanmıştır. Gruplarda aşağıdaki formül ile dönem sonu verim indeksi hesaplanmıştır (Kryezeu ve ark., 2018).

[Yaşama Gücü (\%) X Canlı Ağırlık (kg) X 100] / (Yaş (gün) X Yemden Yararlanma Oranı)

Gruplarda yer alan bütün hayvanlar deneme sonu Veteriner Fakültesi Deneysel Kesim ve Karkas Değerlendirme Laboratuvarında hayvan refahı ilkeleri dikkate alınarak boyundan kanatma yöntemi ile 56 günlük yaşta kesilmiştir. Deneme gruplarında piliç başına değişken giderler hesaplanarak bir kg pilicin üretim maliyeti bulunmuş, piliç satış geliri ulusal bir marketler zincirinden alınan perakande piliç satış fiyatına göre hesaplanmıştır. Değişken giderler olarak yem gideri, civciv maliyeti ve altlık gideri dikkate alınmış (Çobanoğlu, 2014), giderler toplamı yapılan gerçek harcamalardan hesaplanmıştır. Aşağıdaki formüller ile gruplarda brüt kar ve rantabilite hesaplanmıştır (Aydın ve Unakıtan, 2016).

Brüt kar=perakende karkas satış geliri-değişken giderler toplamı

Rantabilite (\%) = Kar/Maliyet $\times 100$

istatistikî analizler: Denemede incelenen büyüme performansı parametreleri yönünden gruplar arası karşılaştırmalar için tesadüf parseller deneme planı (General Linear Model) kullanılmış, gruplar arası farklılıkların önemli bulunması halinde çoklu karşılaştırmalar için Duncan testi uygulanmıştır (Snedecor ve Cochran, 1989). Canlı ağırlık için karşılaştırmalar bireysel değerlerden, yem tüketimi, yemden yararlanma ile yaşama gücü için tekrarlı grup ortalamaları üzerinden yapılmıştır. Yüzde oranlar önce ArcSin dönüşüme tabi tutulmuş, sonra test uygulanmıştır (Kutsal ve ark., 1990). Analizler SPSS bilgisayar programında yapılmıştır (IBM SPSS, 2009).

\section{Bulgular}

$\mathrm{Bu}$ çalışmada yer alan gruplarda büyüme performansı değerleri tablo 1 de gösterilmiştir. Canlı ağırlık $(P<0.001)$, yem tüketimi $(P<0.001)$ ve yemden yararlanma $(P<0.006)$ üzerine genotipin etkisi önemli bulunurken, barındırma sistemi ise yemden yararlanma $(P<0.019)$ üzerine önemli bir etki göstermiştir. Serbest dolaşımlı free range sistemde yetiştirilen hızlı gelişen piliçlerin yemden yararlanma oranı derin altlık gruba göre belirgin şekilde daha düşük hesaplanmıştır. Yaşama gücü yönünden hem genotipin hem de barındırma sisteminin etkisi önemsiz bulunmuştur. Yavaş ve hızlı gelişen genotiplerde deneme sonu canlı ağırlıklar; 4.588 ve $2.177 \mathrm{~g}$ bulunmuş, verim indeksi değerleri hızlı ve yavaş gelişenlerde 375 ve 221, free range ve derin altlık sistemde 320 ve 276 olarak hesaplanmıştır. En yüksek verim indeksi değeri free 
Tablo 1. Deneme gruplarında büyüme performansı değerleri $(\overline{\boldsymbol{x}} \pm \mathbf{S} \overline{\boldsymbol{x}})$.

\begin{tabular}{|c|c|c|c|c|c|}
\hline Gruplar & Canlı Ağırlık g & Yem Tüketimi g & Yemden Yararlanma & Yaşama Gücü \% & Verim indeksi \\
\hline \multicolumn{6}{|l|}{ Genotip } \\
\hline HG & $4,588 \pm 98$ & $7,856 \pm 105$ & $1,725 \pm 0,042$ & 96,00 & 375 \\
\hline YG & $2,177 \pm 97$ & $4,081 \pm 105$ & $1,914 \pm 0,042$ & 98,00 & 221 \\
\hline \multicolumn{6}{|l|}{ Barındırma } \\
\hline FR & $3,525 \pm 98$ & $5,954 \pm 105$ & $1,741 \pm 0,042$ & 97,00 & 320 \\
\hline DA & $3,240 \pm 96$ & $5,984 \pm 105$ & $1,897 \pm 0,042$ & 97,00 & 276 \\
\hline \multicolumn{6}{|l|}{ Genotipx Barındırma Sistemi } \\
\hline HGxFR & $4,862 \pm 139$ & $7,859 \pm 149$ & $1,601 \pm 0,060$ & 96,00 & 416 \\
\hline HGXDA & $4,314 \pm 140$ & $7,854 \pm 148$ & $1,849 \pm 0,060$ & 96,00 & 335 \\
\hline YGXFR & $2,187 \pm 138$ & $4,048 \pm 148$ & $1,882 \pm 0,060$ & 98,00 & 225 \\
\hline YGXDA & $2,167 \pm 139$ & $4,114 \pm 150$ & $1,946 \pm 0,060$ & 98,00 & 217 \\
\hline \multicolumn{6}{|l|}{ ANOVA } \\
\hline Genotip & 0,001 & 0,001 & 0,006 & ö.d & \\
\hline Barındırma Sistemi & 0,057 & 0,840 & 0,019 & ö.d & \\
\hline Genotip x Barındırma Sistemi & 0,076 & 0,815 & 0,143 & ö.d & \\
\hline
\end{tabular}

HG: Hızlı Gelişen, YG:Yavaş gelişen, FG: Free-range, DA: Derin altlık, ö.d, önemli değil

range sistemde yetiştirilen hızlı gelişen piliçlerde (483), en düşük derin altlık barındırmada yetiştirilen yavaş gelişen piliçlerde (217) hesaplanmıştır.

Çalışmada deneme sonu hesaplanan karkas geliri, karkas maliyeti, brüt kar ve karlılık oranları tablo 2'de gösterilmiştir. Serbest dolaşımlı free range sistemde yetiştirilen yavaş gelişen piliçlerde brüt kar ve karlılık düzeyi en yüksek bulunurken, derin altlık sistemde yetiştirilen hızlı gelişen piliçlerde bu değerler en düşük hesaplanmıştır.

Tablo 2. Gruplarda karkas satış geliri ve maliyetler ile brüt kar ve karlılık düzeyleri

\begin{tabular}{lcccc}
\hline Gruplar & $\begin{array}{c}\text { Karkas } \\
\text { geliri/kg } \\
\text { (TL) }\end{array}$ & $\begin{array}{c}\text { Karkas } \\
\text { maliyeti/kg } \\
\text { (TL) }\end{array}$ & $\begin{array}{c}\text { Brüt } \\
\text { Kar } \\
\text { (TL) }\end{array}$ & $\begin{array}{c}\text { Karlılık } \\
\text { (\%) }\end{array}$ \\
\hline HG x FR & 10,35 & 5,89 & 4,46 & 75,85 \\
HG x DA & 10,35 & 6,63 & 3,72 & 56,12 \\
YG x FR & 19,29 & 7,06 & 12,23 & 173,35 \\
YG x DA & 16,97 & 7,23 & 9,75 & 134,87 \\
\hline
\end{tabular}

HG:Hızlı Gelişen, YG:Yavaş gelişen, FG:Free-range, DA:Derin altlık

Deneme gruplarında maliyetler değişen giderler üzerinden hesaplanmış, karkas üretim maliyetlerinde yem giderinin toplam içindeki payı hızlı gelişenlerde yaklaşık \%95 yavaş gelişenlerde \%91 düzeyinde olarak hesaplanmıştır (Tablo 3).

Tablo 3. Gruplarda yem, civciv ve altlık giderlerinin toplam içindeki dağılımı (\%).

\begin{tabular}{lccc}
\hline Gruplar & Yem gideri & $\begin{array}{l}\text { Civciv } \\
\text { gideri }\end{array}$ & $\begin{array}{c}\text { Altlık } \\
\text { gideri }\end{array}$ \\
\hline HG x FR & 95,02 & 4,19 & 0,78 \\
HG x DA & 95,02 & 4,20 & 0,78 \\
YG x FR & 90,77 & 7,78 & 1,45 \\
YG x DA & 90,96 & 7,66 & 1,43 \\
\hline
\end{tabular}

HG: Hızlı Gelişen, YG: Yavaş gelişen, FG: Free-range, DA: Derin altıık

\section{Tartışma ve Sonuç}

Piliç eti üretiminde büyüme performansının karşılaştırılmasında canlı ağırlık, yemden yararlanma, yaşama gücü ve bunların tamamının tek bir rakamla ifade edildiği büyüme performans indeksi ya da verim indeksi en önemli parametrelerdir (Bird 1955; Kryeziu ve ark. 2018). Kuluçka çıkış ağırlığı 38-40 g kadar oldukça düşük olan etçi genotipler 42 günlük kesim yaşında 2,5-2,7 kg canlı ağırlığa ulaşmaktadırlar (Branciari ve ark., 2009). Kesim yaşı tüketici talebi ve pazar koşullarına göre değişmekle birlikte ticari koşullarda yapılan geleneksel piliç eti üretiminde genelde 39 gün, free range piliç eti üretiminde 59 gün, organik piliç eti üretiminde ise 70 gündür (British Poultry Council, 2017).

Bu çalışmada beklenildiği gibi; hızlı gelişen etlik piliçlerde deneme sonu canlı ağırlık kazancı yavaş gelişen genotiplere göre önemli düzeyde daha yüksek bulunmuştur. Hızlı gelişen piliçlerin canlı ağırlık kazancı yönünden yüksek bir genetik potansiyele sahip olmaları bu farklılığın başlıca nedenidir (Fanatico, 2007; Harlander ve Hausler, 2009; Sarıca ve Yamak, 2010). Bu çalışmada elde edilen bu bulgular Branciari ve ark. (2009) ve Wang ve ark. (2009)' nın araştırma sonuçları ile benzerlik göstermektedir. Serbest dolaşmlı free-range sistemde yetiştirilen hızlı gelişen piliçlerin canlı ağırlıkları derin altlık sistemde yetiştirilenlere göre önemli düzeyde daha yüksek bulunmuştur. Bu sistemde hayvanlar gezinti/otlama esnasında bir miktar enerji harcasa da gezinti alanındaki yeşil bitkiler, tohumlar, solucanlar ve böceklerden elde ettiği ilave besin maddelerinden dolayı derin altlık sistemde yetiştirilen piliçlere göre daha yüksek canlı ağırlık kazanmıştır. Ponte ve ark. (2008) mera 
kullanımının broyler büyüme performansı ve et kalitesi üzerine etkisini belirlemek amacıyla yaptıkları bir araştırmada free-range barındırma grubunda canlı ağırlığın derin altlıklı sistemde büyütülen piliçlere göre daha yüksek olduğunu bildirmişlerdir. Bu çalışmada elde edilen sonuçtan farklı olarak bazı araştırmalarda (Almasi ve ark., 2015; Stadig ve ark., 2016) canlı ağırlığın derin altlık sistemde yetiştirilen piliçlerde free-range piliçlere göre daha yüksek bulunduğu bildirilirken, bazı araştırmalarda (Dal Bosco ve ark., 2014; Moyle ve ark., 2014) barındırma sisteminin canlı ağırlık üzerine etkisinin istatistiksel olarak önemli olmadığı bildirilmiştir. Bu çalışmada piliç başına toplam yem tüketimi bakımından genotipin etkisi önemli bulunurken, barındırma sisteminin etkisi önemsiz bulunmuştur. Bununla uyumlu olarak yapılan bazı çalışmalarda, hızlı gelişen piliçlerin yavaş gelişen piliçlere göre daha fazla yem tüketimine sahip oldukları bildirilmiştir (Branciari ve ark., 2009; Quentin ve ark., 2003). Bu çalışmada hem hızlı gelişen hem de yavaş gelişen piliçlerin derin altlık ve serbest dolaşımlı free range sistemde deneme sonu toplam yem tüketimleri birbirine yakın bulunmuştur. Free range sistemde hayvanlar dışarı çıkıp gezinme ve otlama imkânı bulsa da gezinti otlama alanının mera kalitesi hayvanların yem tüketimi üzerine önemli bir katkı sağlamamıştır. Bu çalışmada barındırma sisteminin piliç başına yem tüketimi üzerine etkisi ile elde edilen değerler, Ponte ve ark. (2008), Dal Bosco ve ark. (2014) ile Tong ve ark. (2014) ve Stadig ve ark. (2016)'nın bildirişleri ile benzerlik göstermektedir. Bu çalışmada yemden yararlanma üzerine genotip ve barındırma sisteminin etkisi önemli bulunmuştur $(P<0.006$ ve $P<0.009)$. Deneme sonu yemden yararlanma değeri free-range sistemde yetiştirilen hızlı gelişenlerde en düşük bulunurken (1.601), derin altlık sistemde yetiştirilen yavaş gelişenlerde en yüksek bulunmuştur (1.946). Bu çalışmada elde edilen bulguların aksine Mikulski ve ark. (2011) tarafından yemden yararlanma açısından genotipler arasındaki farklııkların istatistiksel olarak önemli olmadığı bildirilmiştir. Bu çalışma ile uyumlu olarak Fanatico ve ark. (2006) tarafından hızlı gelişen piliçlerde yavaş gelişen piliçlere göre daha düşük bir yemden yararlanma oranı elde edildiği bildirilmiştir. Genetik etki yanında yavaş gelişen piliçlerin daha hareketli olmalarından dolayı bu hayvanlarda kilogram canlı ağırlık kazancı için yem tüketiminin daha yüksek olduğu söylenebilir. Bu çalışmada deneme sonu yemden yararlanma için hesaplanan değer Pavlovski ve ark. (2009)'nın Arbor Acres ve RedBro genotipleri için bildirdiği değerlerden daha yüksektir. Hızı gelişen piliçler için derin altlık sistemde hesaplanan deneme sonu yemden yararlanma oranı Fouad ve ark. (2008), Almedia ve ark. (2017) ile Li ve ark. (2017)' nın derin altlık sistemde hızlı gelişen piliçler için bildirdiği değerden daha düşüktür. Yavaş gelişen piliçler için serbest dolaşımlı free range ve derin altlık sistemde hesaplanan yemden yararlanma oranı Fanatico ve ark. (2008) ile Diktaş ve ark. (2015)'nın aynı barındırma sistemlerinde yavaş gelişenler için bildirdiği yemden yararlanma oranından çok daha iyidir. Yavaş ve hızlı gelişen genotipler için deneme sonu hesaplanan yemden yararlanma oranı (1.725 ve 1.914) Koçer ve ark. (2018)' nın bildirdiği değerlerden daha iyidir (2.03 ve 3.16). Aynı şekilde hızlı gelişen piliçler için serbest dolaşımlı free range sistemde hesaplanan yemden yararlanma oranı (1.601) Poltowicz ve Doktor (2011) tarafından bu barındırma sisteminde benzer genotipler için bildirilen değerden daha iyi bulunmuştur.

$\mathrm{Bu}$ çalışmada derin altlık ve free-range sistemde yetiştirilen etlik piliçlerde yaşama gücü \%95' in üzerinde hesaplanmış, yaşama gücü üzerine barındırma sistemi ve genotipin etkisi önemsiz bulunmuştur. Etlik piliç yetiştiriciliğinde bir üretim döneminde \%5' e kadar ölümlerin kabul edilebilir olduğu dikkate alınırsa guruplardaki yaşama gücü değerleri ticari koşullar için kabul edilebilir sınırlardadır (Çelik ve ark., 2007). Çalışmada, deneme sonu yaşama gücü oranı, hızlı ve yavaş gelişen piliç gruplarında sırasıyla $\% 96$ ve $\% 98$ olup, free-range ve derin altlıklı barındırma gruplarında aynı oranda \%97 olarak belirlenmiştir. Bu araştırmada, hızlı ve yavaş gelişen piliç gruplarında elde edilen yaşama gücü oranları, Quentin ve ark. (2003) ile Branciari ve ark. (2009) ve Mikulski ve ark. (2011)'nın bildirişleriyle benzerlik göstermektedir. Free-range ve derin altlıklı barındırma gruplarında elde edilen yaşama gücü oranları, Pavlovski ve ark. (2009), Mikulski ve ark. (2011), Dal Bosco ve ark. (2014) ile Tong ve ark. (2014) ve Ohara ve ark. (2015)' nın bulgularıyla genelde benzerdir. Bu çalışmada elde edilen yaşama gücü değerleri hızlı ve yavaş gelişen piliçlerin kullanıldığı geleneksel ve organik piliç eti üretiminde elde edilen değerlerden biraz daha düşük olsa da genelde benzerdir (Bokkers ve De Boer 2009; Gocsik ve ark., 2016). Free range ve derin altlık sistemde yetiştirilen yavaş gelişenler için bulunan yaşama gücü değeri Diktaş ve ark. (2015)' nın bildirdiğinden daha yüksektir. Hızlı gelişenler için derin altlık sistemde tespit edilen yaşama gücü değerleri Li ve ark. (2017) ile Almedia ve ark. (2017) 'in bildirdiği değerlerden daha yüksek bulunmuştur. Ticari piliç eti üretiminde üretim dönemi ya da genotiplerin belirli standartlara göre performanslarını değerlendirmek için Avrupa Verimlilik İndeksi olarak tanımlanan genel bir verim indeksi geliştirilmiştir. Bu performans indeksinin sınıflandırılmasında 140-150 arasındaki değer zayıf, 150-170 arasındaki değerler orta, 170-185 
arasındaki değerler iyi ve 190'dan daha büyük değerler de mükemmel olarak belirlenmiştir (Şenköylü, 1991). Günümüz ticari koşullarında ise bu değerin 300-350 arasında değiştiği bildirilmiştir (Poultry Performance Plus, 2019). Buna göre bu çalışmada yer alan gruplarda hesaplanan verim indeksi değerlerinin tamamı Şenköylü (1991)' nün bildirdiğine göre mükemmel sınıfında yer almaktadır. Günümüz ticari koşulları için bildirilen değerler ile karşılaştırıldığında ise free-range sistemde yetiştirilen hızlı gelişen grubun verim indeksi üst sınırdan daha yüksek derin altlık sistemde yetiştirilen hızlı gelişenler için hesaplanan değer ise bildirilen sınırlar arasındadır. Yavaş gelişenler için bu çalışmada hem free-range hem derin altlık sistemde hesaplanan indeks değerleri ticari koşullar için bildirilen değerden daha düşüktür. Ticari koşullar için hesaplanan bu değerin hızlı gelişen genotiplere göre hesaplanmış bir değer olduğunu da dikkate almak gerekir. Free range barındırma sisteminde hesaplanan indeks değeri ticari koşullar için bildirilen değere benzer iken, derin altlık için hesaplanan değer bildirilenin altında bulunmuştur.

Piliç eti üretiminde en büyük maliyet unsuru yem olup, sabit giderlerin eşit olduğu koşullarda işletmeler ya da gruplar arası karşılaştırmalarda faaliyetlerin başarısı genelde brüt karlılık düzeyine göre, değişken ve sabit giderlerin tamamı dikkate alınarak yapılan karşılaştırmalar ise genelde net kar ve karlılık düzeyine göre yapılmaktadır (Yılmaz ve ark., 2010). Sarıca ve ark. (2014) tarafından farklı etlik piliç genotipleri ile yapılan bir çalışmada toplam masrafların \%92'sini değişken giderler, \%8'ini ise sabit giderlerin oluşturduğu, değişken masraflar içinde en önemli payı ise \%75 ile yem maliyetinin oluşturduğu bildirilmiştir. Bu çalışmada yem, civciv ve altlık giderinden ibaret değişken giderlerde en büyük pay \%90-95 ile yem giderinde olmuştur. Hızlı gelişenlerde yemin toplam içindeki payı yavaş gelişenlere göre daha yüksek bulunmuştur. Yavaş gelişenlerde karkas satış gelirinin daha yüksek olmasından dolayı brüt, kar ve karlılık düzeyi yavaş gelişenlerde hızlı gelişenlere göre çok daha yüksek hesaplanmıştur. Serbest dolaşımlı free-range sistemde yetiştirilen hızlı gelişenler derin altlık sistemde yetiştirilen hızlı gelişenlerden, yine serbest dolaşmılı free-range sistemde yetiştirilen yavaş gelişenler, derin altıkta yetiştirilen yavaş gelişenlerden daha yüksek brüt kar ve karlılık göstermişlerdir. Çiçekgil (2018) Türkiye'de kanatlı hayvan sektöründe üretim maliyetinin en önemli kısmını \%68 oran ile yem giderlerinin oluşturduğunu bildirmiştir. Petek (1999) Bursa ili yakın çevrede faaliyet gösteren ticari ve sözleşmeli piliç eti üretim işletmelerinde brüt kar oranını \%25 ve $\% 68$, net kar oranını $\% 17$ ve $\% 26$ bulmuş, bu işletmelerde değişken giderlerin toplam maliyet içindeki payını ise \%91 ve \%56 olarak bildirmiştir. Hızlı gelişen piliçlerde karkas maliyetinin daha düşük olmasının bu hayvanlarda tüketilen yemi ete dönüştürme kabiliyetlerinin çok daha yüksek olmasından dolayı olduğu düşünülmektedir. Avrupa genelinde organik ya da free-range sistemlerden üretilmiş piliçlerin satış fiyatının konvansiyonel sistemdeki piliçlere göre iki kat daha fazla olduğu bildirilmiştir (Westgren, 1999). Bu durum Türkiye'de de hemen hemen aynı olup, yavaş gelişen piliçlerin perakende karkas gelirinin hızlı gelişen piliçlere göre daha yüksek olduğu tespit edilmiştir. Bu çalışma bulgusu, Husak ve ark. (2008)'nın çalışmasındaki bulgu ile benzerlik göstermektedir. Daha yüksek satış fiyatı yavaş gelişen piliçlerde daha yüksek brüt kar ve karlılık oranı elde edilmesini sağlamıştır.

$\mathrm{Bu}$ çalışmada hızlı gelişen piliçlerin büyüme performansı daha iyi bulunsa da daha yüksek satış fiyatına bağlı olarak yavaş gelişen piliçlerin ekonomik performansının daha iyi olduğu tespit edilmiştir. Serbest dolaşımlı free-range barındırmada yavaş ve hızlı gelişen piliçlerin her ikisinin de büyüme ve ekonomik performansı derin altık sistemde yetiştirilenlere göre daha yüksek bulunmuştur. Yakın gelecekte ticari üretimde; serbest dolaşımlı free-range üretimde hızlı gelişen piliçlerin, konvansiyonel derin altlık kapalı barınaklarda yavaş gelişen piliçlerin kullanımının giderek yaygınlaşacağı düşünülmektedir. Bu gelişimde daha doğal ve hayvan refahına daha uygun sistemlerde üretilmiş piliç etine olan tüketici ilgisi önemli bir rol oynayacaktır.

\section{Kaynaklar}

Almasi A, Andrassyne BG, Milisits G, Kustosne PO, Suto Z, 2015: Effects of different rearing systems on muscle and meat quality traits of slow- and mediumgrowing male chickens. Br Poult Sci, 56, 320-324.

Almeida EA, Souza LFA, Anna ACS, Bahiense RN, Macari M, Furlan RL, 2017: Poultry rearing on perforated plastic floors and the effect on air quality, growth performance, and carcass injuries-Experiment 1: Thermal Comfort. Poult Sci, 96, 3155-3162.

Anonim, 1980: Muestreo de pastos. In EEPF "Indio Hatuey, (ed.) Taller del IV Seminario Científico de la EEPF Indio Hatuey", Matanzas, Cuba.

Anonim, 2007: Council Regulation (EC) No 834/2007 of 28 June 2007 on organic production and labelling of organic products and repealing Regulation (EEC) No 2092/91 https://eur-lex.europa.eu/legalcontent/EN/TXT/PDF/?uri=CELEX:32007R0834\&fro $\mathrm{m}=\mathrm{EN}$, Erişim tarihi 10.12.2020.

Anonim, 2018. Minimum Ventilation Rates for Todays Broiler.

http://tr.aviagen.com/assets/Tech_Center/Broiler_B reeder_Tech_Articles/English/AviagenBrief- 
VentilationRates-2018-EN.pdf ${ }_{2}$ Erişim tarihi 30.11. 2020.

Anonim, 2020: Kanatlı Verileri. Tarım ve Orman Bakanlığ Gıda Kontrol Genel Müdürlüğü. https://www.tarimorman.gov.tr/sgb/belgeler/sagm enuveriler/haygem.pdf, Erişim tarihi; 23.10.2020.

Appleby MC, Hughes BO, Elson HA, 1992: Poultry Production Systems. CABI Publishing. UK.

Aydın B, Unakıtan G, 2016: Trakya Bölgesinde faaliyet gösteren tarım işletmelerinin karşılaştırmalı ekonomik analizi. Anadolu Tarım Bilimleri Dergisi. doi: 10.7161/omuanajas.260978

Bird HR, 1955: "Performance index" of growing chickens. Poult Sci, 34, 1163-1164.

Bokkers EAM, De Boer IJM, 2009: Economic, ecological, and social performance of conventional and organic broiler production in the Netherlands. Br Poult Sci, 50, 546-557.

Branciari R, Mugnai C, Mammoli R, Miraglia D, Ranucci D, Dal Bosco A, Castellini C, 2009: Effect of genotype and rearing system on chicken behavior and muscle fiber characteristics1. J Anim Sci, 87, 4109-4117.

British Poultry Council, 2017: In praise of free range. British Poultry Council. https://www.britishpoultry.org.uk/in-praise-of-freerange/, Erişim tarihi; 15.06.2020.

Ceylan N, 2018: Organik ve Geleneksel (Konvansiyonel) Üretilmiş Tavuk Eti (Yanlış Bilinenler ve Gerçekler) https://acikders.ankara.edu.tr/ pluginfile.php/ 69120/mod_resource/content/0/KB10_10Hafta_O rganik_Modelde_Kanatl\%C4\%B1_besleme_2018.pdf , Erişim tarihi; 19 Mart 2019.

Çelik A, (015: Ankara'da otlanan ve otlanmayan iki meranın botanik kompozisyonu ile ot veriminin Karşılaştırılması. Yüksek lisans tezi, Ankara Üniversitesi Fen Bilimleri Enstitüsü, Ankara.

Çelik S, Özmelioğlu K, Kararali A, Özdemir V, 2007: Etlik Piliç Yetiştiriciliği. https://www.tarimorman.gov.tr/HAYGEM/Belgeler/ Hayvanc\%C4\%B1l\%C4\%B1k/Kanat|\%C4\%B1\%20Yeti \%C5\%9Ftiricili\%C4\%9Fi/Etlik\%20Pili\%C3\%A7\%20Yeti stiriciligi.pdf, Erişim tarihi; 20.06.2020.

Çiçekgil Z, 2019: Tarım Ürünleri Piyasaları Tavuk Eti. Tarımsal Ekonomi ve Politika Geliştirme Enstitüsü (TEPGE).

rastirma.tarimorman.gov.tr/tepge/Belgeler/PDF\%20 Tarım\%20Ürünleri\%20Piyasaları/2019-

Ocak\%20Tarım\%20Ürünleri\%20Raporu/2019-

Ocak\%20Tavuk\%20Eti.pdf, Erişim tarihi; 20.06.2020.

Çobanoğlu F, Kucukyimaz K, Cinar M, Bozkurt M, Catlı AU, Bintaş E, 2014: Comparing the Profitability of Organic and Conventional Broiler Production. Rev Bras Cienc Avic, 16, 89-96.

Da Silva PV, Van der Werf HM, Soares SR, Corson MS, 2014: Environmental impacts of French and Brazilian broiler chicken production scenarios: an LCA approach. J Environ Manage, 133, 222-231.

Dal Bosco A, Mugnai C, Rosati A, Paoletti A, Caporali S, Castellini C, 2014: Effect of range enrichment on performance, behavior, and forage intake of freerange chickens. The J App Poult Res, 23, 137-145.

Diktaş M, Şekeroğlu A, Duman M, Yıldırım A, 2015: Effect of Different Housing Systems on Production and
Blood Profile of Slow-Growing Broilers. Kafkas Üniv Vet Fak Derg, 4, 521-526. Fanatico A, Pillai PB, Cavitt LC, Emmert JL, Meulllent JF, Owens CM, 2006: Evaluation of Slower-Growing Broiler Genotypes Grown with and Without Outdoor Access: Sensory Attributes. Poult Sci, 85, 337-343.

Fanatico AC, Pillai PB, Hester PY, Falcobne C, Mench JA, Owens CM, Emmert JL, 2008: Performance, Livability, and Carcass Yield of Slow- and FastGrowing Chicken Genotypes Fed Low-Nutrient or Standard Diets and Raised Indoors or with Outdoor Access. Poult Sci 87, 1012-1021.

Fouad MA, Abdelrazek AH, Badaway ESM, 2008: Bird welfare and economics under two management alternatives on commercial scales. Int J Poult Sci, 7, 1167-1173.

Gocsik É, Brooshooft SD, De Jong IC, Saatkamp HW, 2016: Cost-efficiency of animal welfare in broiler production systems: A pilot study using the Welfare Quality ${ }^{\circledast}$ assessment protocol. Agric Sys, 146, 55-69.

Grandin T, 2015: Improving Animal Welfare: A Practical Approach. 2nd Edition, pp: 255, CABI, Colorado State University, USA,

Harlander-MA, Häusler K, 2009: Understanding feather eating behaviour in laying hens. Appl. Animal Behav Sci, 117, 35-41.

Husak R, Sebranek J, Bregendahl K, 2008: A survey of commercially available broilers marketed as organic, free-range, and conventional broilers for cooked meat yields, meat composition, and relative value. Poult Sci, 87, 2367-2376.

Jones Ta, Berk J, 2012: Alternative systems for meat chcikens and turkeys: Production, health and welfare, chapter 14: CAB International (Ed. V.Sand.lans, PM Hocking). Poultry Science Symposium Series 3, 250-272.

Karaarslan S, 2015: Etlik piliçlerde refah kriteri olarak bacak sağlığı, korku ve stres parametreleri üzerine aydınlatma, yerleşim sıklığı ve tünek kullanımının etkileri. Doktora tezi, Adnan Menderes Üniversitesi Sağlık Bilimleri Enstitüsü Zootekni Anabilim Dalı, Aydın.

Koçer B, Bozkurt M, Ege, Tüzün AE, Konak R, Olgun O, 2018: Effects of a meal feeding regimen and the availability of fresh alfalfa on growth performance and meat and bone quality of broiler genotypes. $\mathrm{Br}$ Poult Sci, 59, 318-329.

Kryeziu AJ, Mestani N, Berisha Sh, Kamberi MA, 2018: The European performance indicators of broiler chickens as influenced by stocking density and sex. Agron Res, 16, 483491.

Kutsal A, Alpan O, Arpacık R, 1990: İstatistik Uygulamalar. Bizim Büro Basımevi, Ankara.

Legrand A, Ajuda I, Locqueville J, Pencalet E, 2017: Developing higher welfare broiler production in France: a case study from a French cooperative. $X$ th European Symposium on Poultry Welfare. 19-22 June 2017, Ploufragan, France.

Li Y, Luo C, Wang J, Guo F, 2017: Effects of different raising systems on growth performance, carcass, and meat quality of medium-growing chickens. J App Anim Res, 45, 326-330. 
Li H, Wen X, Alphin R, Zhou Z, 2017: Effects of two different broiler flooring systems on production performances, welfare, and environment under commercial production conditions. Poult Sci, 96, 1108-1119.

Miao ZH, Glatz PC, Ru YJ, 2005: "Free-range Poultry Production - A Review." Asian-Australasian J Anim Sci, 18, 113-132.

Mikulski D, Celej J, Jankowski J, Majewska T, Mikulska M, 2011: Growth Performance, Carcass Traits and Meat Quality of Slower-growing and Fast-growing Chickens Raised with and without Outdoor Access. Asian-Australasian J Anim Sci, 24, 1407-1416.

Moyle JR, Arsi K, Woo-Ming, Arambel H, Fanatico A, Blore PJ, Clark FD, Donoghue DJ, Donoghue AM, 2014: Growth performance of fast-growing broilers reared under different types of production systems with outdoor access: Implications for organic and alternative production systems. The J App Poult Res, 23, 1-9.

Ohara A, Oyakawa C, Yoshihara Y, Ninomiya S, Sato S, 2015: Effect of Environmental Enrichment on the Behavior and Welfare of Japanese Broilers at a Commercial Farm. The J Poult Sci, 52, 323-330.

Pavlovski Z, Skrbic Z, Lukic M, 2009: The effect of genotype and housing system on production results of fattening chickens. Biotech In Anim Husband, 25, 221-229.

Petek M, 1999: Bursa il merkezine yakın çevre broyler işletmelerinde farklı genotiplerin üretim parametreleri ve ekonomik verimlilik. Lalahan Hayvancılık Araş Enst Derg, 39, 61- 72.

Poltowicz K, Doktor J, 2011: The effect of free-range raising on performance, carcass attributes and meat quality of broiler chickens. Anim Sci Papers and Rep, 29, 139-149.

Ponte PIP, 2008: Effect of pasture biomass intake on growth performance and meat quality of free-range broilers. PhD thesis, Tese de Doutoramento em Ciência e Tecnologia Animal, Lisboa.

Ponte PIP, Alves SP, Bessa RJB et al., 2008: Influence of Pasture Intake on the Fatty Acid Composition, and Cholesterol, Tocopherols, and Tocotrienols Content in Meat from Free-Range Broilers. Poult Sci, 87, 8088.

Poultry Performance Plus, 2019: Performance Index. https://poultryperformanceplus.com/informationdatabase/broilers/157-production-index, Erişim tarihi; 09.04.2019.

Quentin M, Bouvarel I, Berri C, Le Bihan-Duval E, Baeza E, Jego Y, Picard M, 2003: Growth, carcass composition and meat quality response to dietary concentrations in fast-, medium- and slow-growing commercial broilers. Anim Res, 52, 65-77.

Sarıca M, Ceyhan V, Yamak US, 2014: Yavaş Gelişen Sentetik Etlik Piliç Genotipleri ile Ticari Etlik Piliçlerin
Büyüme, Karkas Özellikleri ve Bazı Ekonomik Parametreler Bakımından Karşılaştırılması. J Agric Sci, 22, 20-31.

Sarıca M, Yamak US, 2010: Yavaş gelişen etlik piliçlerin özellikleri ve geliştirilmesi. Anadolu J Agric Sci, 25, 61-67.

Snedecor GW, Cochran, WG, 1989: Statistical Methods. Eighth Edition, lowa State University Press, USA.

SPSS Inc. Released, 2009: PASW Statistics for Windows, Version 18.0. Chicago: SPSS Inc.

Stadig LM, Rodenburg TB, Reubens B, Aerts J, Duquane B, Tuyttens FAM, 2016: Effects of free-range access on production parameters and meat quality, composition and taste in slow-growing broiler chickens. Poult Sci, 5, 2971-2978.

Şenköylü N, 1991: Modern Tavuk Üretimi. Anadolu Matbaa ve Ticaret Koll. Sti. İstanbul.

Taylor PS, Hemsworth PH, Groves PJ, Gebhardt-Henrich SG, Loup Rault J, 2018: Ranging behavior relates to welfare indicators pre- and post-range access in commercial free-range broilers. Poult Sci, 97, 18611871.

Tong HB, Wang Q, Lu J, Zou JM, Chang LL, Fu SY, 2014: Effect of free-range days on a local chicken breed: Growth performance, carcass yield, meat quality, and lymphoid organ index1. Poult Sci, 93, 18831889.

Wang KH, Shi SR, Dou TC, Sun HJ, 2009: Effect of a freerange raising system on growth performance, carcass yield, and meat quality of slow-growing chicken. Poult Sci, 88, 2219-2223.

Westgren RE, 1999: Delivering Food Safety, Food Quality, and Sustainable Production Practices: The Label Rouge Poultry System in France. Am J Agric Evon, 81, 1107.

Van Horne PLM, Achterbosch TJ, 2008: Animal Welfare in Poultry Production Systems: Impact of EU Standards on World Trade. World's Poult Sci J, 64, 40-52.

Yenilmez F, Uruk E, 2016: Free-Range Sistemi, Avantaj ve Dezavantajları. Nevşehir Bilim ve Teknoloji Dergisi TARGID DOI: 10.17100/nevbiltek.62680.

Yılmaz F, İnan iH, Hurma H, 2010: Tarım İşletmelerinder Ekonomik Analiz İçin Bir Bilgisayar Yazılımı Geliştirilmesi. Türkiye IX. Tarım Ekonomisi Kongresi, Şanlıurfa, 80-87.

*Bu makale "Serbest Dolaşımlı (Free-range) Barındırma Sistemi ve Yavaş Gelişen Etlik Piliç Genotiplerinin Büyüme Performansı, Hayvan Refahı ve Davranışları ile Ayak Sağlığı ve Ekonomik Verimlilik Üzerine Etkileri" konu başlıkı doktora tezinden özetlenmiştir.

${ }^{* *}$ Yazışma Adresi: Metin Petek

Bursa Uludağ Universitesi Veteriner Fakultesi Zootekni Anabilim Dalı 16059 Gorukle / Bursa, Turkey.

e-mail: petek@uludag.edu.tr 